\title{
Epidemiology of Blackleg (Leptosphaeria maculans) of Canola (Brassica napus) in Relation to Maturation of Pseudothecia and Discharge of Ascospores in Western Australia
}

\author{
R. Khangura, J. Speijers, M. J. Barbetti, M. U. Salam, and A. J. Diggle
}

First, second, and fifth authors: Department of Agriculture and Food Western Australia, Locked Bag No. 4, Bentley Delivery Center, South Perth, WA 6983, Australia; third author: School of Plant Biology, The University of Western Australia, 35 Stirling Highway, Crawley, WA 6009, Australia; and fourth author: Centre for Cropping Systems, Department of Agriculture and Food Western Australia, P.O. Box 483, Northam, WA 6401, Australia.

Accepted for publication 26 March 2007.

\begin{abstract}
Khangura, R., Speijers, J., Barbetti, M. J., Salam, M. U., and Diggle, A. J. 2007. Epidemiology of blackleg (Leptosphaeria maculans) of canola (Brassica napus) in relation to maturation of pseudothecia and discharge of ascospores in Western Australia. Phytopathology 97:1011-1021.

The timing of maturation of pseudothecia and discharge of ascospores of the blackleg fungus (Leptosphaeria maculans) is critical in relation to infection early in the cropping season of canola. During 1998 to 2000, development of pseudothecia was investigated on residues of the previous year's canola crop collected from four agroclimatically different locations: Mount Barker (southern high rainfall), Wongan Hills (central medium rainfall), Merredin (central low rainfall), and East Chapman (northern low rainfall) in Western Australia. The pseudothecia matured on residues at different times after harvest in various regions. In general, pseudothecia maturity occurred earlier in the high-rainfall areas than in medium- and low-rainfall areas. An ascospore discharge pattern was investigated from residues of crop from the previous year (6-month-old residues) at three locations-Mount Barker, Wongan Hills, and East Chapman in Western Australia-and from 18-month-old residues that

were burnt and raked in the previous year at Mount Barker and East Chapman. Ascospore discharge commenced earlier in high-rainfall ( $>450$ $\mathrm{mm})$ areas (Mount Barker) and late in northern low-rainfall $(<325 \mathrm{~mm})$ areas (East Chapman). The major ascospore showers took place during May (late autumn) and June (early winter) at Mount Barker and during July and August (mid- to late winter) at East Chapman. The number of ascospores discharged was extremely low at East Chapman compared with Mount Barker. At both locations, the number of ascospores discharged from 18-month-old residues that were raked and burnt in the previous year were only $\approx 10 \%$ of those discharged from previous year's residues left undisturbed. The discharge of ascospores on any given day was negatively correlated with accumulated temperatures, maximum temperature, evaporation, minimum and maximum soil temperatures, and solar radiation and was positively correlated with the minimum temperature, rain, and minimum relative humidity. This is the first report describing how pseudothecia mature on residues in different rainfall areas in Western Australia, and it potentially can be used in developing a forecasting system to avoid the synchronization of major ascospore showers with the maximum susceptibility period of canola seedlings.
\end{abstract}

Blackleg (Phoma stem canker) caused by Leptosphaeria maculans (Desm.) Ces. \& De Not. is the most important and serious disease of canola (Brassica napus L.) worldwide and causes significant yield loss $(24,28)$. Canola is now a major oilseed crop in Western Australia, with an estimated area of 420,000 ha sown in 2004 (4). L. maculans is carried over on canola residues, and increased canola production in Western Australia over the past few years has resulted in the accumulation of large amounts of infested residues in fields and, hence, increased the inoculum pressure for subsequent canola crops. Canola cultivars with greater resistance to blackleg are required to cope with this increased amount of inoculum pressure. However, the current Australian canola cultivars, despite the very good resistance of mature plants, suffer serious yield losses from blackleg if attacked at an early seedling stage. In Western Australia, blackleg caused losses of up to \$20 million in 1998 (10) and up to \$50 million during 1999 (M. J. Barbetti, unpublished data). Thus, blackleg remains a major constraint to profitable and sustainable canola production in Western Australia.

L. maculans perennates in residues after harvest and the ambient weather provides conditions favorable for the initiation,

Corresponding author: R. Khangura; E-mail address: rkhangura@agric.wa.gov.au

doi:10.1094/PHYTO-97-8-1011

(C) 2007 The American Phytopathological Society development, and maturation of pseudothecia. Ascospores released from pseudothecia produced on infested residues serve as a source of primary inoculum $(2,3,15,16,29)$ and cause primary infection on canola seedlings in late autumn or early winter. In Western Australia, blackleg generally is managed through the use of resistant cultivars and adapted cultural practices (avoiding sowing into and close to infested residues) and by using fungicides such as flutriafol (Impact) $(12,13)$. Manipulating time of sowing can shift the period of maximum susceptibility to blackleg infection and the first significant discharge of ascospores, coinciding with the maximum susceptibility stage $(1,5,11,13)$, and fungicide applications reduce the final canker severity if applied at an optimum time (28). Therefore, to develop effective control strategies for blackleg it is essential to understand the epidemiology of the disease, including the timing of pseudothecia maturation and the effects of meteorological variables on pseudothecia maturation and dispersal of ascospores. Limited studies have been conducted on the development of pseudothecia under natural conditions $(18,19,22,26)$. Currently, there is no information available on the temporal pattern of maturation of pseudothecia in the Mediterranean-type climate of Western Australia. Investigations have been carried out on the ascospore discharge pattern of L. maculans in North America $(7,8,16,20)$, Europe $(5,9,18,28)$, and eastern Australia (15). However, the information on the ascospore discharge pattern of the blackleg pathogen under Western Australian environments is scanty and inconclusive (2). There- 
fore, the objectives of this study were to (i) determine the factors affecting maturation of pseudothecia and the discharge pattern of ascospores of $L$. maculans in a range of climatic conditions, including the high-, medium-, and low-rainfall regions of the Western Australian grain belt; and (ii) propose a forecasting technique to predict the temporal dynamics and intensity of ascospore showers in order to manage the disease through time of sowing by reducing the chance of ascospore inception during the critical stage of maximum susceptibility of canola to blackleg.

\section{MATERIALS AND METHODS}

Monitoring maturation of pseudothecia on residues. Canola stems from the previous year's crop were collected during 1998, 1999, and 2000 from four different agroclimatic zones of Western Australia. The locations were Mount Barker $\left(34.38^{\circ} \mathrm{S}\right.$ and $\left.117.32^{\circ} \mathrm{E}\right)$, Wongan Hills $\left(30.51^{\circ} \mathrm{S}\right.$ and $\left.116.44^{\circ} \mathrm{E}\right)$, Merredin $\left(31.31^{\circ} \mathrm{S}\right.$ and $\left.118.10^{\circ} \mathrm{E}\right)$, and East Chapman $\left(28.30^{\circ} \mathrm{S}\right.$ and $\left.115.05^{\circ} \mathrm{E}\right)$ to represent high-rainfall $(>450 \mathrm{~mm})$, medium-rainfall (325 to $450 \mathrm{~mm}$ ), low-rainfall $(<325 \mathrm{~mm}$ ), and northern (low rainfall with warmer winter temperatures) areas, respectively, of Western Australia. The crops usually are harvested in late November to December in Mount Barker and early November in Merredin, Wongan Hills, and East Chapman. In 1998, 20 canola stems were collected in the last week of March and subsequently at weekly intervals from a field of the previous year's crop from each of the above four locations. In 1999 and 2000, $\approx 10$ stems each from four different fields were collected in the second week of March and subsequently at weekly intervals from all the above four locations, except for Wongan Hills in 2000, where stems were collected from only two fields. In 2000, 10 stems also were collected at the same times from 18-month-old residues from each of the above locations to examine the timing of pseudothecia maturation on older residues. Each stem was observed at three positions (root, crown, and upper stem) for the maturation of pseudothecia of blackleg under the microscope. Aqueous squash mounts of pseudothecia were made and observed under the light microscope $(\times 200)$. A minimum of 20 pseudothecia were observed from each stem. Pseudothecia were regarded as mature when the majority of asci contained eight ascospores. In all, $\approx 10,000$ stems were observed for this study during 1998 to 2000 .

Ascospore discharge pattern. The ascospore discharge pattern of L. maculans was investigated for 3 years during 1999 to 2001. In 1999, ascospore discharge was studied from residues of the previous year's crop (6-month-old residues) at Mount Barker. In 2000, ascospore discharge was studied from 6- and 18-month-old residues at Mount Barker and East Chapman. The 18-month-old residues were raked and burnt in the previous year at both locations. In 2001, the ascospore discharge was studied from 6- and 18-month-old residues at East Chapman and from 6-month old residues at Wongan Hills. A 7-day recording volumetric spore trap (Burkard Scientific, Rickmansworth, Hertfordshire, England) was set up in the centre of a 20-by-20-m area of each field containing either 6- or 18-month-old residues. At each location, the spore trap was set up before the maturation of pseudothecia in order to capture the first discharge of ascospores and was run throughout the season to determine when ascospores stopped discharging. At Mount Barker, the spore trapping commenced in the first week of May 1999 and 13 March 2000. At East Chapman, spore trapping commenced on 28 March and 4 April in 2000 and 2001, respectively. At Wongan Hills, the spore trapping commenced on 28 March 2001. The spore trap was out of order for four periods in 1999 (22 to 27 May, 5 to 7 June, 12 to 14 June, and 25 to 28 September) at Mount Barker, once in 2000 (26 April to 8 May) at Mount Barker, and once in 2000 (20 to 27 June) at East Chapman. The spore trap sampled air at $\approx 10$ liters $/$ min and the sampling orifice was located $0.5 \mathrm{~m}$ above the ground. The spore-trapping surface (melinex tape) was coated with a thin layer of vaseline. The tape was changed weekly, then cut into daily segments $(48 \mathrm{~mm})$ and mounted on glass slides. The melinex tapes were not stained because the L. maculans ascospores are fairly large in size and are easily identifiable. Ascospores were counted for every second hour of the day, and daily counts were calculated from the hourly counts. The mean daily ascospore concentration per cubic meter of the sampled air was derived from these counts using the air volume sampling rate of the spore trap as described in the methods of Guo and Fernando (7) with some modifications. The final concentration of ascospore per cubic meter was corrected for the actual concentration of ascospores per cubic meter of air.

Weather patterns between locations. The daily meteorological data, including minimum and maximum air temperature, minimum and maximum relative humidity (minRH and maxRH), minimum and maximum soil temperature (minSoilTemp and maxSoilTemp), rainfall, solar radiation (solarRad), daily mean wind speed (meanWind), maximum wind speed (maxHourSpd), hours with wind speed $>29 \mathrm{~km} / \mathrm{h}$ (hrsWind29), and evaporation (evaporation) were accessed from automatic weather stations operated by the Western Australian Department of Agriculture and Food at Wongan Hills, Mount Barker, and Merredin. The number of hours a weather station was not operating also was recorded. No measured data was available for East Chapman; therefore, an interpolated data set provided by the Queensland Department of National Resources and Mines was used. In addition, for each site, minimum and maximum air temperature and rainfall was available from the Australian Bureau of Meteorology (BOM) for a nearby site.

The automatic weather station data contained many missing values due to weather stations failing to operate for either a few hours or days at a time. In addition, values were considered to be unreliable when $>4 \mathrm{~h}$ of daily record was missing. When reliable values of maximum and minimum temperatures and rainfall were unavailable, they were estimated using linear regression based on either (i) data from adjacent days or (ii) data for the same day from a nearby BOM site. The choice of regression was based on which one gave the best predictions and whether data from adjacent days and BOM data was available. Missing values for minimum temperature (minTemp) and rainfall (Rain) at East Chapman, Merredin, and Wongan Hills were estimated from a linear regression for relationship (ii) at each site. Missing values for minTemp and Rain at Mount Barker were estimated using (i) unless the adjacent values were missing, in which case they were estimated from a linear regression for relationship (ii). Missing values for maximum temperature (maxTemp) were estimated using (i) unless the adjacent values were missing, in which case they were estimated from a linear regression for relationship (ii). Average temperature on each day (meanTemp) and mean weekly temperature (MWT) were calculated using these values. Accumulated rainfall (accRain) and daily average temperature (accTemp) were calculated at each site commencing at the beginning of each year. Accumulated adjusted temperature (accAdjTemp) also was calculated at each site commencing at the beginning of each year by only cumulating mean daily temperatures for days with rainfall (23). On the basis that mature pseudothecia can develop at temperatures up to $25^{\circ} \mathrm{C}$ but that lower temperatures are more favorable (24), the difference between average temperature and $25^{\circ} \mathrm{C}$ was accumulated both with (accAdjTempLT25) and without (accTempLT25) the rainfall adjustment (22), and the number of days with average temperatures $<25^{\circ} \mathrm{C}$ was accumulated both with (AccAdjDaysLT25) and without (AccDaysLT25) the rainfall adjustment. Relationships between weather variables were examined using a biplot. AccDaysLT25 and AccAdjDaysLT25 were not included in the biplots because of their high correlations with accTempLT25 $(r=0.950)$ and accAdjTempLT25 $(r=0.990)$, respectively. 
Statistical analysis. GenStat edition 8 was used for all statistical analyses.

Pseudothecia maturation. The data contained a large number of observations for percent stems with mature pseudothecia (\%SMP) of either 0 or 100 on successive assessment dates at the beginning and end of the collection period, respectively. Only the last two zero values and the first two values of 100 (in time order) were retained for each field in each site and year. The discarded values contained no additional information regarding the pseudothecia maturation. Simple correlations were calculated between \%SMP and weather variables.

A generalized linear model was fitted to the data with the dependent variable, the number of stems with mature pseudothecia on each day (R), assumed to have a binomial distribution. Day of year $\left(\mathrm{X}_{1}\right)$ and weather variables $\left(\mathrm{X}_{2}, \mathrm{X}_{3}\right.$, and so on), year $\left(Y_{i}\right)\left(i=1,2,3\right.$, and 4), location $\left(L_{j}\right)(j=1,2$, and 3), and yearlocation $\left(\mathrm{YL}_{\mathrm{ij}}\right)$ were the independent variables. The model can be written as $\log _{10}[\mathrm{P} /(100-\mathrm{P})]=\mu+\mathrm{aX} \mathrm{X}_{1}+\mathrm{bX}_{2}+\ldots+\mathrm{Y}_{\mathrm{i}}+\mathrm{L}_{\mathrm{j}}+$ $\mathrm{YL}_{\mathrm{ij}}$, where $\mathrm{P}$ is the expected value of $\% \mathrm{SMP}(100 \times \mathrm{R} /$ total number of stems) and $\mu, a, b$, and so on are constants. Weather variables were chosen on the basis of the biplots and correlations with \%SMP, with the proviso that they were measured at all sites. Regression errors were modeled using the binomial distribution. The intention was to find a model that predicted percent SMP well using environmental variables while excluding year and year-location effects (and possibly location effects) so as to predict the pseudothecia maturation for each location from environmental data. Initially, all independent variables apart from year and location effects were included in the model. A backward elimination process was used to remove nonsignificant terms from the model. Location and year effects then were added to the model to determine their importance. Values fitted by the regressions were plotted.

In order to compare \%SMP and ascospore counts, low-order polynomials were fitted to actual \%SMP versus day (East Chapman 2000 and 2001, Mount Barker 1999 and 2000, and Wongan Hills 2001) and these were used to estimate \%SMP on days when ascospores were trapped.

Ascospore discharge. At each site, the proportion of the final total ascospore concentration that was discharged on each day was calculated. At the beginning and end of the measurement period, there were long periods when no ascospores were trapped or there were very low ascospore numbers on isolated days. These counts were considered to provide no additional information regarding the ascospore discharge. Adjusted ascospore counts of $<10$ at the beginning of the season were discarded unless they were immediately followed by an ascospore count $>10$. Similarly, at the end of the season, ascospore counts $<10$ were discarded unless they were immediately preceded by an ascospore count $>10$. Only one zero count prior to the first positive ascospore count and only one zero count after the last positive count were included in the analysis. Simple correlations were calculated between the logarithm of ascospores discharged on each day and weather variables.

A generalized linear model was fitted to the data under the assumption that the dependent variable, the number of ascospores discharged on each day, would have a Poisson distribution. Day of year $\left(\mathrm{X}_{1}\right)$, AccDayLT25 $\left(\mathrm{X}_{2}\right)$ and weather variables $\left(\mathrm{X}_{3}, \mathrm{X}_{4}\right.$, and so on), year $\left(Y_{i}\right)(i=1,2$, and 3$)$, location $\left(L_{j}\right)(j=1,2$, and 3$)$, age $\left(\mathrm{A}_{\mathrm{k}}\right)(\mathrm{k}=1$ and 2$)$, year-age $\left(\mathrm{YA}_{\mathrm{ik}}\right)$, and location-age $\left(\mathrm{LA}_{\mathrm{jk}}\right)$ were the independent variables. The coefficients associated with day of year and AccDayLT25 were allowed to change with year and location. The model can be written as $\log _{10}(C)=\mu+a X_{1}+b$ $X_{2}+c X_{3}+\ldots \ldots+Y_{i}+L_{j}+A_{k}+Y_{i k}+L_{j k}+m_{j} X_{1}+n_{k} X_{1}+o_{j} X_{2}$ $+\mathrm{p}_{\mathrm{k}} \mathrm{X}_{2}$, where $\mathrm{C}$ is the expected ascospore discharge and $\mu, \mathrm{a}, \mathrm{b}$, $\mathrm{m}_{\mathrm{j}}$, and $\mathrm{n}_{\mathrm{k}}$ are constants. Weather variables were chosen on the basis of biplots and correlations with ascospore discharges. Because there are only five year-location combinations, the location-year estimation is not estimable. Regression errors were modeled using the Poisson distribution. Initially, all independent variables apart from terms including year and location were included in the model. A backward elimination process was used to remove nonsignificant terms from the model. Terms including location and year then were added to the model to determine their importance. Fitted ascospore discharges from the regressions then were accumulated and these values were plotted with the actual values.

\section{RESULTS}

Weather patterns between locations. The average monthly summer (January to April) temperature was 5 to $7^{\circ} \mathrm{C}$ higher at Merredin, Wongan Hills, and East Chapman compared with Mount Barker in all years of study. However, the amount of monthly rainfall was variable at all these locations in different years. The climatic conditions were comparatively cooler at Mount Barker compared with the rest of the areas.

The biplot of the first two principal components (accounting for 33 and $21 \%$ of the variance, respectively) provides a snapshot of the weather data for days on which ascospores were collected (Fig. 1). There were high correlations between all the accumulated temperature and rain variables ( $r=0.414$ to 0.960$)$ and high correlations between the daily temperature variables $(r=0.412$ to $0.921)$ but relatively lower correlations between the two groups of variables ( $r=-0.211$ to 0.525$)$. Minimum and maximum relative humidity were negatively correlated with minimum and maximum air temperatures $(r=-0.216$ and -0.359 , respectively; $P<$ $0.001)$ and soil temperatures $(r=-0.401$ and -0.286 , respectively; $P<0.001)$. Solar radiation was highly correlated with evaporation $(P=0.912, P<0.001)$, both of which were moderately correlated with daily temperatures and accumulated temperatures $(r=0.098$ to 0.771 ). Daily rainfall and wind data did not contribute very much to either of the first two principal components. A biplot of the first and third (accounting for $15 \%$ of the variance) principal components indicated that wind data and rainfall were correlated ( $r=0.248,0.261$, and 0.313 for hrsWind29, maxHourSpd, and meanWind, respectively). Weather data for days on which \%SMP was measured showed correlation patterns similar to those described above. The biplot confirms that, for the days on which the ascospores were trapped, average temperature, which ranged from 6.5 to $26.7^{\circ} \mathrm{C}$ (Table 1), was on average higher at East Chapman and Wongan Hills than at Mount Barker. Minimum relative humidity, which ranged from 12.4 to $98.6 \%$, was on average higher at Mount Barker.

Maturation of pseudothecia on residues. Four key developmental stages of $L$. maculans were identified: pycnidia, immature pseudothecia, pseudothecia with developing asci, and mature pseudothecia with most of asci containing eight fully developed ascospores. Pseudothecial development was preceded by the pycnidial phase at all sites. The pycnidial stage was of longer duration in low- and medium-rainfall areas than in high-rainfall areas (data not shown). It took 2 to 5 weeks for immature pseudothecia to develop asci with mature ascospores. Pseudothecia matured 4 to 12 weeks earlier in the high-rainfall environment (Mount Barker) compared with the medium- and low-rainfall environments during the 3 years of study (Table 2). However, at Wongan Hills and Merredin, sites that represent medium- and low-rainfall areas, respectively, the pseudothecia matured at almost the same time during 1999 and 2000. There was considerable year to year variation in the maturation of pseudothecia within the sites. At East Chapman (northern low-rainfall environment), the pseudothecia matured $\approx 3$ and 6 weeks earlier in 1999 than in 1998 and 2000, respectively. Averaged over 3 years, the time taken for pseudothecia to mature was 99, 164, 165, and 171 days at Mount Barker, Merredin, Wongan Hills, and East Chapman, respectively. There was field to field variation in the 
percentage of stems with mature pseudothecia at all sites during 1999 and 2000. However, no difference in the timing of pseudothecia maturity was observed on residues from cultivars with different levels of blackleg resistance (data not shown). The pseudothecia on 18-month-old residues matured at almost the same time as on 6-month-old residues at all four sites (Table 2). The old pseudothecia on 18-month-old residues did not survive over summer and were desiccated and had shriveled ascospores that were not viable for infection.

Significant correlations were observed between \%SMP and MWT, accRain, accAdjTemp, accTempT25, accAdjTempLT25, and maxSoilTemp. Likewise, weak but significant correlations were observed between \%SMP and maxRH, minSoilTemp, meanTemp, and minRH. Correlations between \%SMP and all other weather variables were not significant (Table 1). An accumulated analysis of variance showing the significance of adding terms to the regression model indicated that a model including day of year, accumulated temperature $<25^{\circ} \mathrm{C}$ adjusted for rainfall, accumulated rainfall, maximum relative humidity and soil temperature, solar radiation, rainfall, and location explained $72.2 \%$ of the deviance in \%SMP (Table 3). Observed values for \%SMP for each field and each location for 1999 and fitted values based on the model, including significant weather variables and location effects, are presented in Figure 2.

Ascospore discharge pattern. At Mount Barker, the first discharge of ascospores from 6-month-old residues was detected on 5 May and 17 March during 1999 and 2000, respectively (Fig. $3 \mathrm{~A}$ and $\mathrm{B})$. The maximum numbers of ascospores were dis- charged in the month of June 1999 and May 2000. The ascospores were discharged in much higher numbers in 1999 than in 2000. The discharges of ascospores from 18-month-old residues in 2000 followed a similar pattern except that the ascospore number was extremely low (Fig. 3C). In all, 20\% of the season's ascospores were discharged by 31 May (47 days after onset of pseudothecia maturation) and 12 April (30 days after onset of pseudothecia maturation) from 6-month-old residues during 1999 and 2000, respectively. Likewise, $70 \%$ of the season's ascospores were discharged by 6 July ( 83 days after onset of pseudothecia maturation) and 18 June (97 days after onset of pseudothecia maturation) during 1999 and 2000, respectively. The mean highest number of ascospores discharged on any given day was 3,371 ascospores $/ \mathrm{m}^{3}$ on 22 June 1999 and 2,150 ascospores $/ \mathrm{m}^{3}$ on 27 March 2000. Likewise, the ascospore discharge days with $>1,000$ spores $/ \mathrm{m}^{3}$ / day were higher in 1999 than in 2000. The number of days with ascospore discharge recorded in a month appeared to be related to the number of rain days up to the peak of the ascospore showers discharge. However, there appeared to be no relationship between ascospore discharge and rain days once the ascospore discharge started diminishing, especially in high-rainfall areas (data not shown).

At East Chapman in 2000, the ascospore discharge from 6month-old residues started in July, reached its peak in August, and then declined in September. No ascospores were discharged in October. The first ascospores were detected on 19 July and 4 July in 2000 and 2001, respectively. The highest number of ascospores was discharged between 11 August and 7 September, whereas

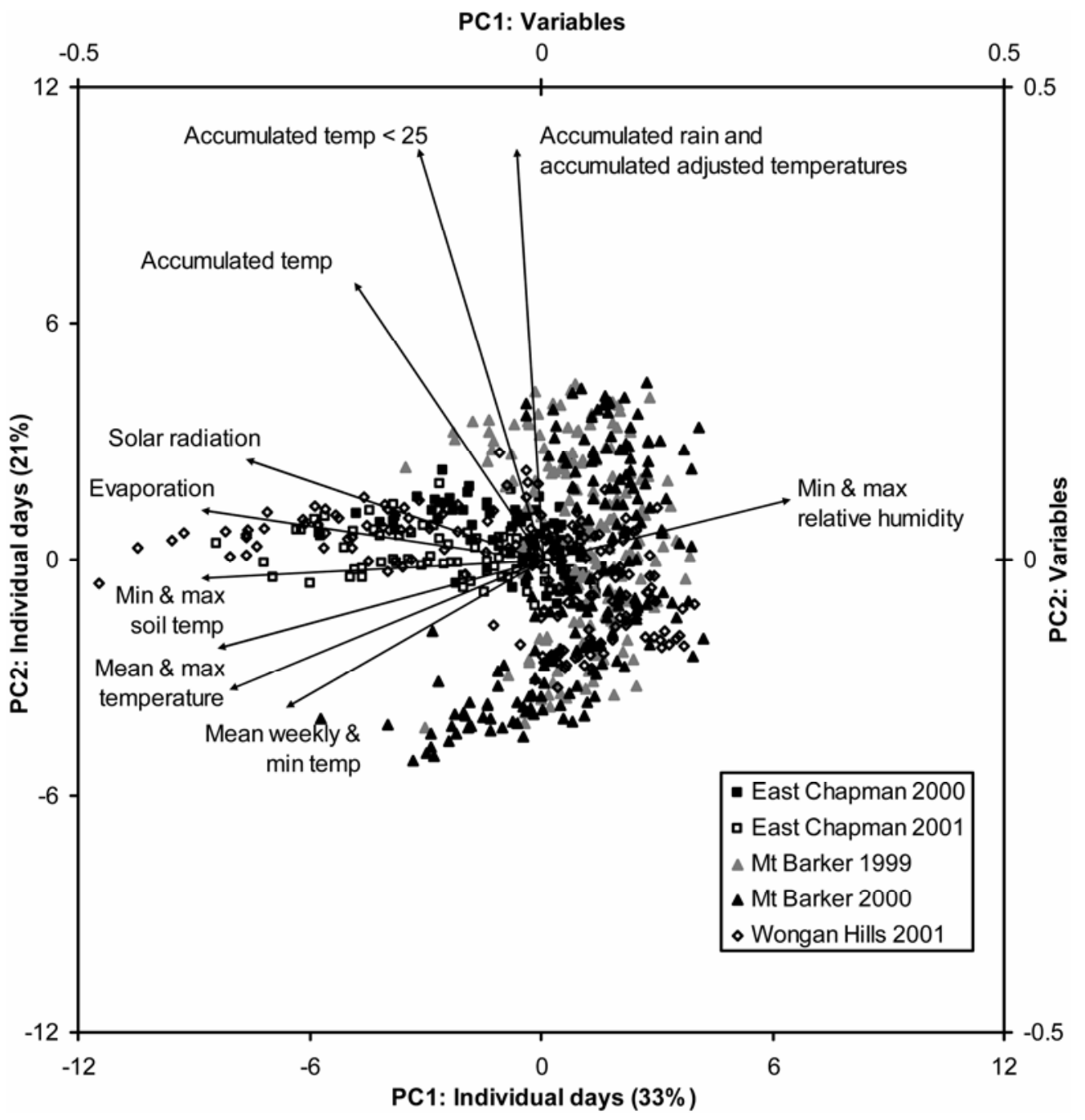

Fig. 1. Biplots for weather data during period of ascospore discharges of Leptosphaeria maculans showing principal components 1 (33\%) versus 2 (21\%). 
there were no ascospores discharged after 29 September and no rainfall event occurred during this period (Fig. 3D). A similar pattern of ascospore discharge was observed in 2001 (Fig. 3E). The discharges of ascospores from 18-month-old residues during 2000 and 2001 followed a similar pattern, except that the asco- spore number was extremely low (Fig. 3F). In all, $20 \%$ of the season's ascospores from 6-month-old residues were discharged by 29 July ( 25 days after onset of pseudothecia maturation) and 29 August (26 days after onset of pseudothecia maturation) in 2000 and 2001, respectively. Likewise, $70 \%$ of the season's

TABLE 1. Minimum and maximum values for weather variables during the period of ascospore discharge of Leptosphaeria maculans and correlations between weather variables and percent stems with mature pseudothecia (\%SMP) and $\log _{10}$ ascospore ${ }^{\mathrm{a}}$

\begin{tabular}{lcccc}
\hline Variable $^{\text {b }}$ & Minimum & Maximum & Correlation with \%SMP & ${\text { Correlation with } \log _{10} \text { ascospore count }}^{*}$ \\
\hline maxTemp & 8.9 & 32.8 & -0.114 & $-0.104^{*}$ \\
minTemp & -0.1 & 20.5 & -0.114 & $0.255^{*}$ \\
meanTemp & 6.5 & 26.7 & -0.131 & 0.064 \\
accTemp & 1,492 & 5,634 & 0.001 & $-0.267^{*}$ \\
accTempLT25 & 390 & 2,799 & $0.416^{*}$ & $-0.122^{*}$ \\
MWT & 8.4 & 21.6 & $-0.307^{*}$ & $0.264^{*}$ \\
Rain & 0.0 & 27.8 & 0.107 & -0.001 \\
accRain & 51 & 461 & $0.329^{*}$ & -0.027 \\
accAdjTemp & 379 & 1,816 & $0.545^{*}$ & -0.050 \\
accAdjTempLT25 & 122 & 1,507 & $-0.245^{*}$ \\
maxSoilTemp & 8.2 & 40.1 & $-0.636^{*}$ & -0.075 \\
minSoilTemp & 4.4 & 24.0 & -0.136 & $0.123^{*}$ \\
maxRH & 27.4 & 105.6 & 0.175 & $0.227^{*}$ \\
minRH & 12.4 & 98.6 & 0.126 & $-0.339^{*}$ \\
solarRad & 624 & 32,631 & 0.076 & $0.209^{*}$ \\
meanWind & 0 & 25.4. & 0.012 & $0.117^{*}$ \\
maxHourSpd & 0 & 0.094 & $0.111^{*}$ \\
hrsWind29 & 0 & 0.027 & $-0.277^{*}$ \\
Evaporation & 0 & 13.4 & -0.108 & $-0.229^{*}$ \\
DOY & 0 & 324 & $-0.152^{*}$ \\
AccDaysLT25 & 75 & 293 & $\ldots$ & -0.023 \\
AccadjDaysLT25 & 70 & 132 & $\ldots$ & \\
\hline
\end{tabular}

a Asterisks (*) indicate significant correlations at $P<0.001$

b Abbreviations: $\max =$ maximum, $\min =$ minimum, accTemp $=$ accumulated mean temperature, accTempLT $25=$ accumulated difference between average temperature and $25^{\circ} \mathrm{C}$, MWT $=$ mean weekly temperature, accRain = accumulated rain, accAdjTemp = accumulated temperature for days with rainfall, accAdjTempLT25 = accumulated difference between average temperature and $25^{\circ} \mathrm{C}$ for days with rainfall, hrsWind $29=$ number of hours with wind speed exceeding $29 \mathrm{~km} / \mathrm{h}$, solarRad = solar radiation, DOY = day of year, AccDaysLT25 = accumulated number of days with average temperature $<25^{\circ} \mathrm{C}$, and AccadjDaysLT25 $=$ accumulated number of days with average temperature $<25^{\circ} \mathrm{C}$ and with rainfall.

TABLE 2. Dates of onset of pseudothecia maturity at different locations in Western Australia during 1998 to 2000

\begin{tabular}{|c|c|c|c|c|}
\hline \multirow[b]{2}{*}{ Residues, year } & \multicolumn{4}{|c|}{ Location $^{\mathrm{a}}$} \\
\hline & Mount Barker & Wongan Hills $^{\mathrm{b}}$ & Merredin & East Chapman \\
\hline \multicolumn{5}{|c|}{ 6-month-old residues } \\
\hline 1998 & 12 May (132) & 21 June (172) & 6 July (187) & 26 June (179) \\
\hline 1999 & 14 April-12 May (104-132) & 26 May-2 June (146-153) & 14 May-28 June (134-179) & 1-9 June (152-160) \\
\hline 2000 & $13-20 \operatorname{March}(73-80)$ & 22 June (173) & 25 June-2 July (176-183) & 4-11 July (185-192) \\
\hline \multicolumn{5}{|c|}{ 18-month-old residues } \\
\hline 2000 & $20 \operatorname{March}(80)$ & 2 July (183) & 6 July (187) & 4 July (185) \\
\hline
\end{tabular}

${ }^{a}$ Values in parentheses are the days taken to maturity starting from 1 January of each year.

${ }^{\mathrm{b}}$ In Wongan Hills in 2000, stems from only two paddocks were observed.

TABLE 3. Accumulated analysis of variance for percent stems with mature pseudothecia (\%SMP) of Leptosphaeria maculans showing the significance of adding terms to the regression model; percent deviance accounted for by models, including all previous terms; and regression coefficients for the model, including weather variables and location effects

\begin{tabular}{|c|c|c|c|c|c|}
\hline Term added $^{\mathrm{a}}$ & df & Significance & Deviance $(\%)^{\mathrm{b}}$ & Coefficient & Standard error \\
\hline DOY & 1 & $<0.001$ & $\ldots$ & 0.00239 & 0.00486 \\
\hline AccAdjTempLT25 & 1 & $<0.001$ & $\ldots$ & 0.00162 & 0.00093 \\
\hline AccRain & 1 & $<0.001$ & $\ldots$ & 0.00996 & 0.00116 \\
\hline MaxSoilTemp & 1 & $<0.001$ & $\ldots$ & -0.0853 & 0.0198 \\
\hline SolarRad & 1 & 0.003 & $\ldots$ & 0.0000514 & 0.0000137 \\
\hline Rain & 1 & 0.028 & 65.9 & 0.0209 & 0.0123 \\
\hline Location & 3 & $<0.001$ & 72.2 & Int. $^{\mathrm{c}}$ & Int. $^{\mathrm{c}}$ \\
\hline Residual & 210 & $\ldots$ & $\ldots$ & $\ldots$ & $\ldots$ \\
\hline
\end{tabular}

a Abbreviations: DOY $=$ day of year, accAdjTempLT25 = accumulated difference between average temperature and $25^{\circ} \mathrm{C}$ for days with rainfall, accRain $=$ accumulated rain, $\operatorname{maxRH}=$ maximum relative humidity, solarRad = solar radiation .

${ }^{\mathrm{b}}$ Deviance is equivalent to sum of squares in a generalized linear model.

${ }^{\mathrm{c}}$ Intercepts (Int.) for East Chapman, Mount Barker, Merredin, and Wongan Hills are $-5.303,-2.641,-4.517$, and -4.100 with standard errors of 0.947, 0.499, 0.777 , and 0.786 , respectively. 
ascospores were discharged by 24 August (51 days after onset of pseudothecia maturation) and 5 October (63 days after onset of pseudothecia maturation) during 2000 and 2001, respectively. The number of ascospores discharged and rain days per month again showed no relationship.
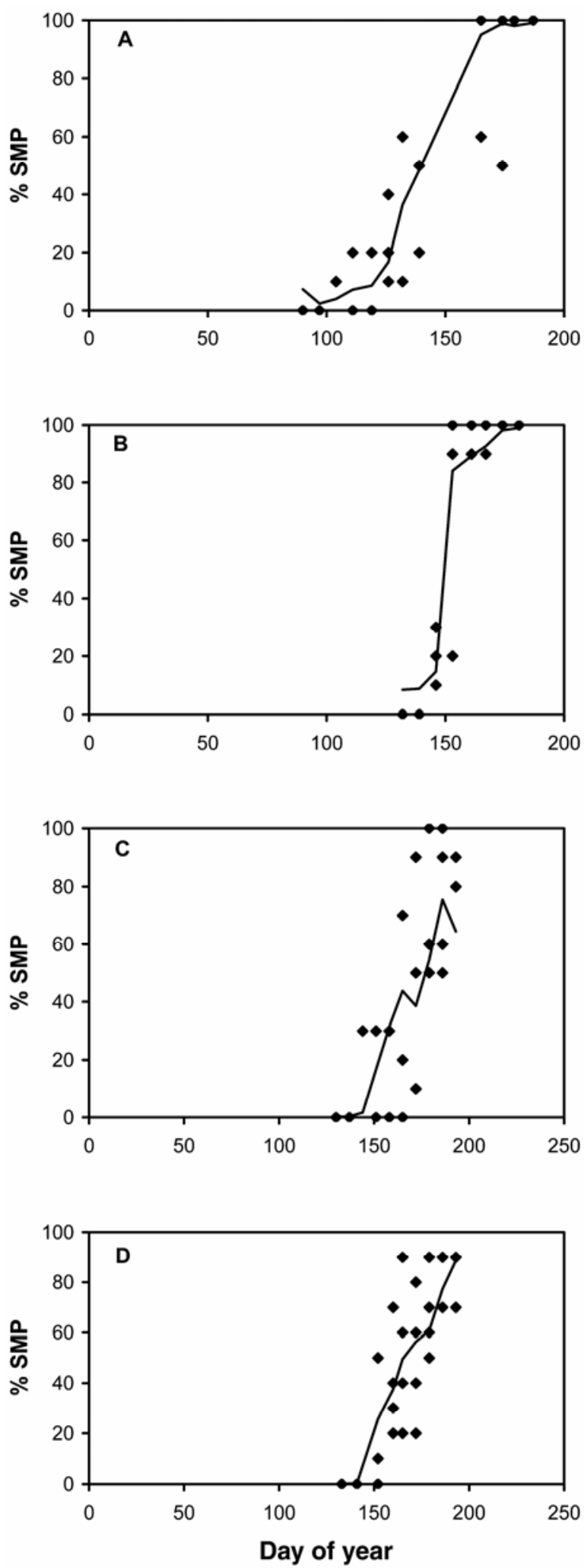

Fig. 2. Observed (dots) and fitted (lines) percent stems with mature pseudothecia (\% SMP) of Leptosphaeria maculans versus day of year at A, Mount Barker; B, Wongan Hills; C, Merredin; and D, East Chapman in 1999. Fitted values have been calculated from a regression model including significant weather variables and location effects.
In medium-rainfall areas (Wongan Hills), the first ascospores were detected on 7 June 2001 and continued as small showers until the end of July, and major ascospores showers were observed after this period (Fig. 3G). In all, 20\% of the season's ascospores were discharged by 29 July ( 52 days after onset of pseudothecia maturation) and $70 \%$ were discharged by 14 September (99 days after onset of pseudothecia maturation). The number of ascospores discharged and rain days per month showed no relationship. The highest number of ascospores discharged on any given day was 802 ascospores $/ \mathrm{m}^{3}$ on 22 September 2001 .

In most of the ascospore discharge events at all locations, ascospores were discharged either during or several hours after the rain event, and the discharge lasted for $\approx 2$ to 6 hours. On some days, the discharge lasted for only $1 \mathrm{~h}$ after the rain event (data not shown). In some instances, a small number of ascospores were discharged in the absence of rain events.

Sufficient data of both variables were available at Mount Barker to show that there was a high correlation between percent stems with mature pseudothecia and the number of ascospores discharged in 1999 on 6-month-old residues $(r=0.88, P=0.008)$, in 2000 on 18-month-old residues $(r=0.95, P<0.001)$, and in 2000 on 6-month-old residues $(r=0.93, P<0.001)$ (Fig. 4). There were significant correlations between $\log _{10}$ accumulated ascospore and a majority of the weather variables (Table 1). The terms included in the model and their significance as they were added to the model are shown in Table 4. A model excluding both location and year effects accounted for $38.3 \%$ of the deviance in $\log$ ascospore counts. Adding location effects $(P<0.001)$ increased the percent deviance and accounted to $38.9 \%$, and adding location-day of year effects increased the percent deviance and accounted to $41.7 \%$. The effect of adding year to the model was not significant. Actual accumulated spore counts for different ages of residues for different locations and years and fitted values based on the model, including significant weather variables and location effects, are shown in Figure 5. The standard deviation of differences between fitted and actual log accumulated ascospore counts for different locations and years (Fig. 5) reflect the relatively poor fit of the model at Wongan Hills in 2001 relative to other sites (Table 5).

\section{DISCUSSION}

Maturation of pseudothecia. The present study highlights the effect of environmental conditions on the maturation of pseudothecia and discharge of ascospores of L. maculans on canola residues. This is the first report describing differences in the development of pseudothecia and the timing of maturation of pseudothecia of L. maculans in canola fields in various rainfall zones of the Mediterranean-type region of Western Australia. In the southwest of Western Australia, canola is sown in mid-May to early June and harvested in December. However, in the central, northeast-central, and northern areas, canola usually is sown at the end of April or in mid-May and harvested in October in the north and in November in the central and northeast-central regions. Maturation of pseudothecia was observed to be a dynamic process, with new pseudothecia continuing to develop and discharge ascospores during the season. In the current studies, it took 73 to 192 days for the first generation of pseudothecia to mature across the locations whereas, in France, pseudothecia matured in relatively shorter times, ranging between 16 and 51 days after harvest (18). Likewise, different patterns of pseudothecia maturation also have been observed under Canadian conditions. In Ontario, the pseudothecia matured 1 month after harvest on stems of last season's rapeseed crop (22) whereas, in western Canada (Saskatchewan), the ascospores began to be produced in pseudothecia on rapeseed or canola stubble 9 months after harvest (20). This difference in timing of pseudothecial maturation in Canadian conditions appeared to be influenced by 
different environmental conditions in these two regions because mean annual rainfall in southern Ontario is approximately double that in Saskatchewan (20). In France, Pérès et al. (18) showed that there was a gradual decrease in the post-summer temperature and cumulative rainy periods prior to and during pseudothecial maturation that conditioned the release of ascospores on the last season's infested residues. In the present studies in high-rainfall areas, the pseudothecia matured when the mean temperature was $\approx 17$ to $19^{\circ} \mathrm{C}$ whereas, in the other areas that had lower rainfall, the maturation occurred at a mean temperature of $\approx 11$ to $14^{\circ} \mathrm{C}$ under natural environmental conditions. However, Pérès et al. (17) reported that, under controlled conditions, a mean temperature of $14^{\circ} \mathrm{C}$ and a high frequency of rainfall $(2.5 \mathrm{~mm}$ every 3 to 4 days) was the best regime for the first generation of pseudothecia. However, in current studies, a significant, strong correlation between \% SMP and accumulated temperature $<25^{\circ} \mathrm{C}$ during the rainy days supports the findings of Salam et al. (24) that 43 favorable days were required for the onset of pseudothecial
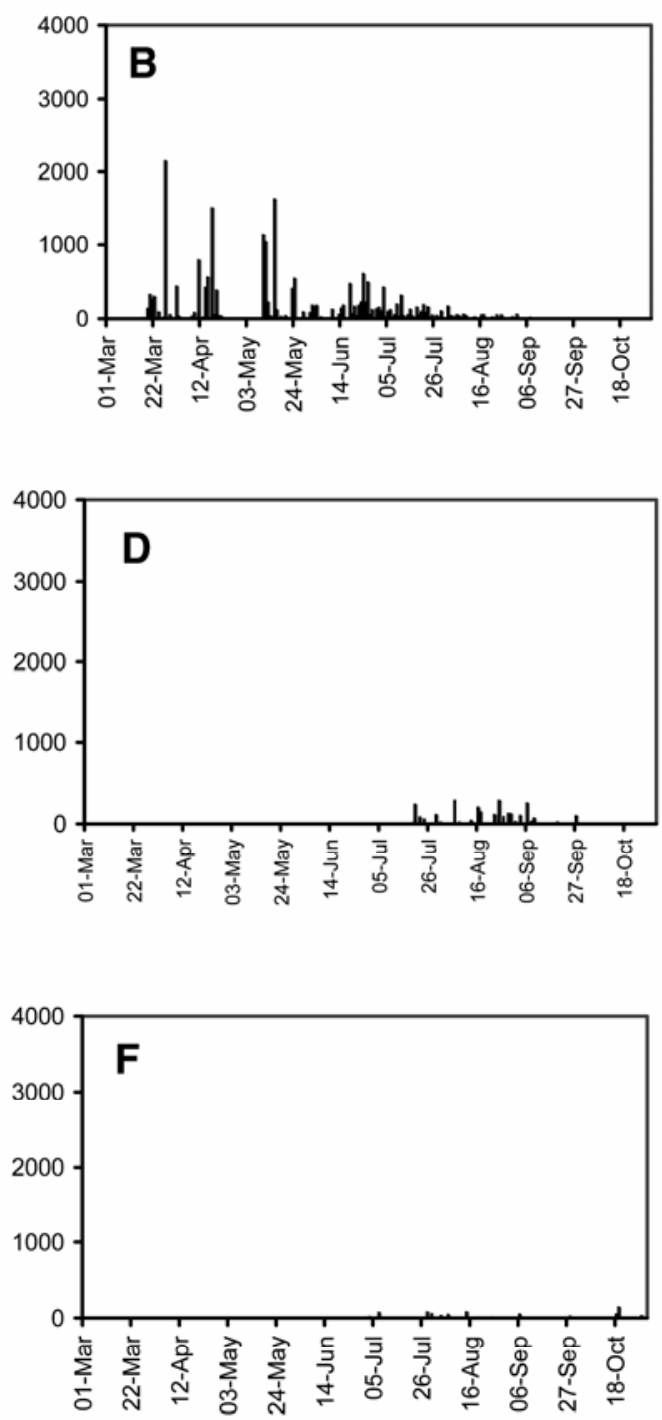

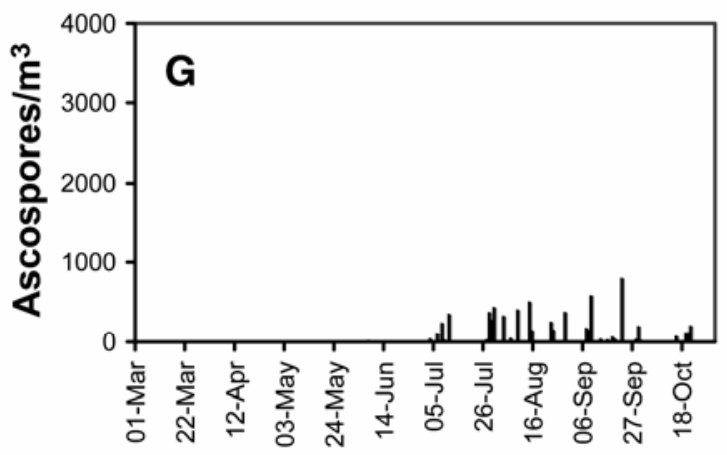

Fig. 3. Daily ascospore discharge pattern of Leptosphaeria maculans at A, Mount Barker on 6-month-old residues during 1999; B, Mount Barker on 6-month-old residues during 2000; C, Mount Barker on 18-month-old residues during 2000; D, East Chapman on 6-month-old residues during 2000; E, East Chapman on 6-month-old residues during 2001; F, East Chapman on 18-month-old residues during 2001; and G, Wongan Hills on 6-month-old residues during 2001. 
maturation under Western Australian environmental conditions. The current study also revealed that the resistance level of the cultivar did not affect timing of pseudothecial maturation on residues as reported by Poisson and Pérès (21). In the present studies, pseudothecia on 6- and 18-month-old residues matured at the same time, indicating a similarity in the pattern of pseudothecia maturation regardless of the age of the residues. However, a marked reduction in the production of new pseudothecia on 18-month-old residues supports previous findings (6) and may indicate a decreased threat to nearby canola crops compared with 6-month-old residues. Although there were significant effects of year in a regression of \%SMP versus weather variables, a model excluding year effects accounted for a large proportion of the variance in \%SMP, indicating that differences in the timing of pseudothecia maturation between locations and years included in this study can be explained largely by climatic variables.

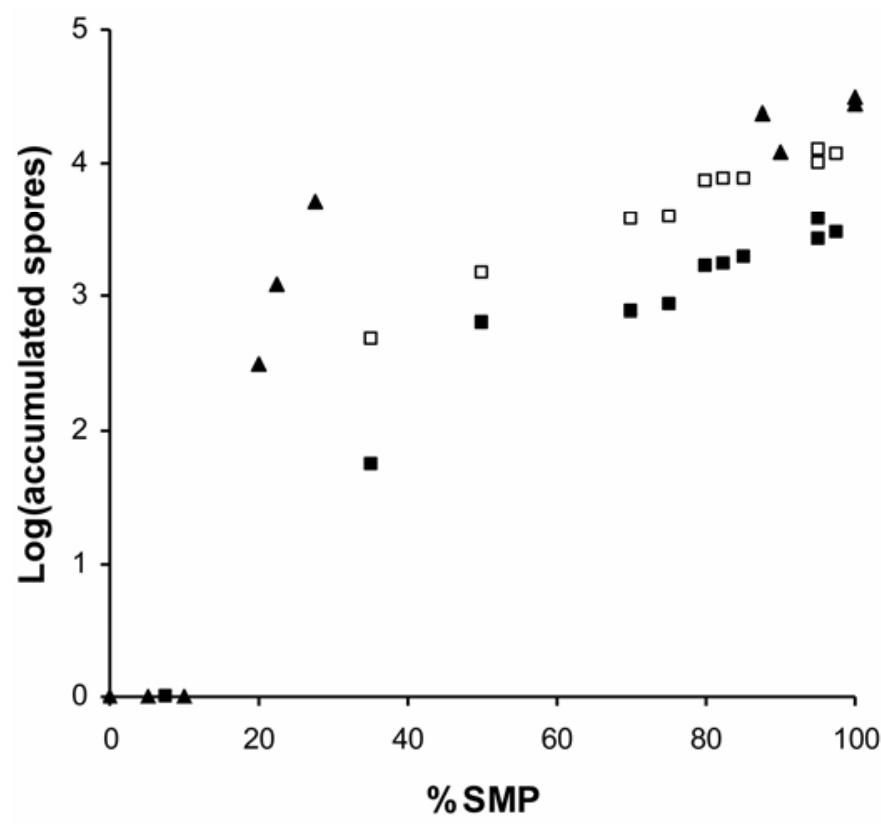

Fig. 4. Relationship between $\log _{10}$ accumulated ascospore discharge of Leptosphaeria maculans and percent stems with mature pseudothecia (\%SMP) at Mount Barker. Solid triangles ( $\mathbf{\Delta})$ indicate on 6-month-old residues in 1999, open squares $(\square)$ indicate on 6-month-old residues in 2000, and solid squares (匹) indicate on 18-month-old residues in 2000.
Ascospore discharge. We observed different patterns of ascospore discharge in different environments and different years. Our studies showed that ascospores began to discharge as soon as they were produced in pseudothecia and, in high-rainfall areas (Mount Barker), the ascospore discharge was high in April to June and then declined in July and August, and very low quantities of ascospores were discharged in October. In contrast, in northern areas with relatively warm climate (East Chapman), the ascospore discharge started late in the season in July and the ascospore concentration was high in August and September, declined in October, and no ascospores were detected in November. The results of the present studies differ from those conducted in eastern Australia by McGee (15), who showed that ascospore discharge from the same crop residues increased greatly between April and May, remained at a high level until August, and then gradually declined until, by January, very few ascospores were discharged. Similarly, Bokor et al. (2) reported from Mount Barker, Western Australia, that concentration of airborne ascospores was high in June, July, and August and declined in September and October. This difference in the ascospore discharge pattern at Mount Barker, Western Australia, in the current and past study (2) further reflects the influence of seasonal conditions on ascospore discharge. The results of the present study have enormous significance in blackleg management, particularly in the northern areas of Western Australia where peaks of ascospore discharge usually occur in July to August. Most of the crops in this area are either bolting or at an early flowering stage at that time. The ascospores discharged in the latter part of the season are regarded as insignificant in terms of causing severe crown cankers because the crops have already passed the most susceptible stage of their growth (20). Therefore, growers in northern or lowrainfall areas do not need to use fungicide to protect their crops if they have the opportunity to sow early because fungicide use in this situation is not likely to improve their economic returns.

There was a daily variation in the discharge of ascospores that could be ascribed to the availability of moisture and the amount of ascospores available for discharge. In some instances, the ascospores were found to be discharged in the absence of rain events, and this could be attributed to dew because this was not measured. These findings agree with observations that, for larger ascospore discharges, rainfall of $>1.0 \mathrm{~mm}$ was required; however, smaller ascospore discharges occurred in light rain or dew (15). Discharge of ascospores during or several hours after the rain events could be attributed to wetness requirements for stimulating pseudothecia to discharge ascospores. If the residues remain dry for several days, it is likely that more time is required to stimulate

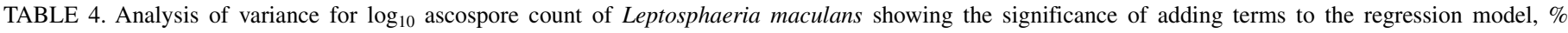
deviance accounted for by models including all previous terms, and regression coefficients for the model including weather variables only

\begin{tabular}{|c|c|c|c|c|c|}
\hline Term added $^{\mathrm{a}}$ & df & Significance & $\%$ Deviance & Coefficient & Standard error \\
\hline DOY & 1 & $<0.001$ & $\ldots$ & -0.538 & 0.334 \\
\hline AccDaysLT25 & 1 & $<0.001$ & $\ldots$ & $\operatorname{Reg}^{\mathrm{b}}$ & $\operatorname{Reg}^{\mathrm{b}}$ \\
\hline AccDaysLT2 $25 \times$ age & $\ldots$ & $<0.001$ & $\ldots$ & Reg $^{b}$ & Reg $^{\mathrm{b}}$ \\
\hline AccTempLT25 & 1 & $<0.001$ & $\ldots$ & 0.0160 & 0.0110 \\
\hline AccRain & 1 & $<0.001$ & $\ldots$ & -0.00038 & 0.00106 \\
\hline AccTemp & 1 & $<0.001$ & $\ldots$ & 0.0186 & 0.0106 \\
\hline MinTemp & 1 & $<0.001$ & $\ldots$ & 0.0783 & 0.0107 \\
\hline Evaporation & 1 & 0.003 & $\ldots$ & -0.1319 & 0.0420 \\
\hline MeanWind & 1 & $<0.001$ & $\ldots$ & 0.0208 & 0.0055 \\
\hline MaxSoilTemp & 1 & $<0.001$ & $\ldots$ & -0.0380 & 0.0107 \\
\hline SolarRad & 1 & 0.002 & 38.3 & 0.0000540 & 0.0000157 \\
\hline Location & 2 & 0.002 & 38.9 & Int. ${ }^{c}$ & Int. ${ }^{c}$ \\
\hline DOY $\times$ location & 2 & $<0.001$ & 41.7 & $\ldots$ & $\ldots$ \\
\hline Age $\times$ location & 2 & 0.419 & 41.7 & $\ldots$ & $\ldots$ \\
\hline Age $\times$ location $\times$ year & 1 & 0.582 & 41.7 & $\ldots$ & $\ldots$ \\
\hline
\end{tabular}

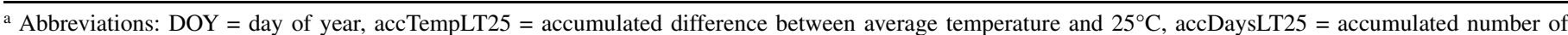
days with average temperature $<25^{\circ} \mathrm{C}$, accRain $=$ accumulated rain, $\min =$ minimum, $\max =$ maximum, and solarRad $=$ solar radiation .

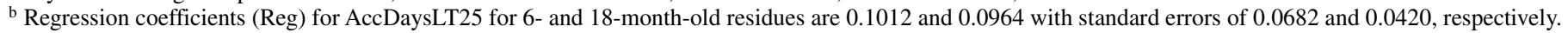

c Intercepts (Int.) for East Chapman, Mount Barker, and Wongan Hills are 0.287, 0.651, and 0.947 with standard errors of 2.580, 0.656, and 1.768, respectively. 
the pseudothecia for ascospore discharge once moisture becomes available. In France, the number of days of rain and the amount of rainfall required to stimulate the very first release of ascospores were fairly close to a constant value regardless of year and geographical location (18).

Like many other pathogens, the ascospore discharge in L. maculans is regarded as a complex process in terms of correlating the ascospore discharge events with the specific environmental variables. Petrie (20) suggested that the production of ascospores on canola stubble in Saskatchewan (Canada) commenced 9 months after harvest and that total rainfall was less important than its frequency, and ascospore numbers were negatively correlated with number of days from April to June or July having a maximum temperature of $\geq 30^{\circ} \mathrm{C}$. In contrast, in Kentucky (United States), the infested canola residues discharged ascospores within 1 week of harvest and significant quantities of spores were released each year in autumn and winter months following crop harvest (8). It is difficult to speculate on factors responsible for
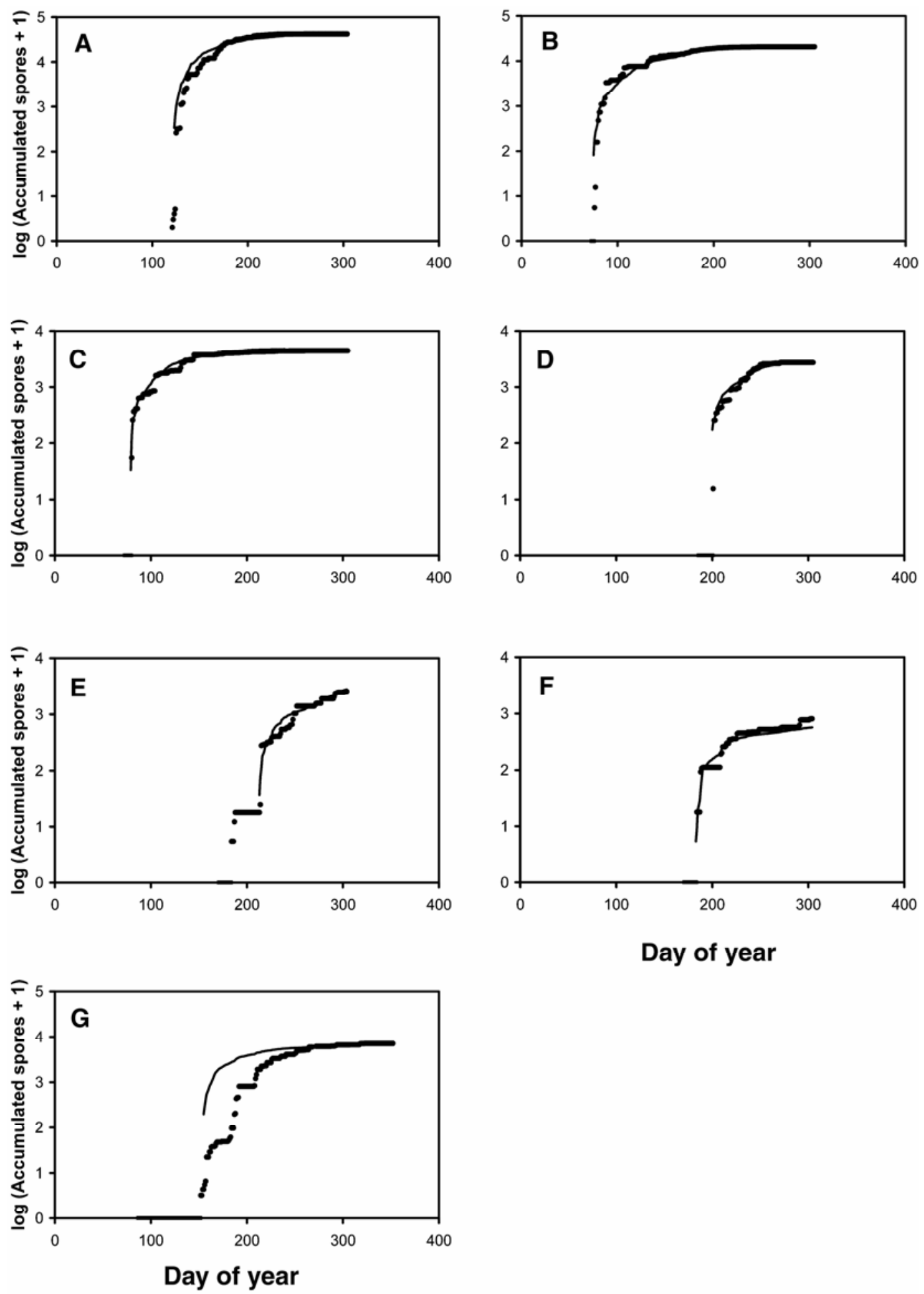

Fig. 5. Observed (dots) and fitted (lines) $\log _{10}$ accumulated ascospore discharge of Leptosphaeria maculans based on a regression model including significant weather variables and location effects. A, Mount Barker on 6-month old residues during 1999; B, Mount Barker on 6-month-old residues during 2000; C, Mount Barker on 18-month-old residues during 2000, D, East Chapman on 6-month-old residues during 2000; E, East Chapman on 6-month-old residues during 2001; F, East Chapman on 18-month-old residues during 2001; and G, Wongan Hills on 6-month-old residues during 2001. 
TABLE 5. Standard deviation of differences between fitted and actual $\log _{10}$ accumulated ascospore counts of Leptosphaeria maculans for different years and locations

\begin{tabular}{lc}
\hline Location & Standard deviation \\
\hline Mount Barker in 1999 on 6-month-old residues & 0.275 \\
Mount Barker in 2000 on 6-month-old residues & 0.223 \\
Mount Barker in 2000 on 18-month-old residues & 0.131 \\
East Chapman in 2000 on 6-month-old residues & 0.299 \\
East Chapman in 2000 on 18-month-old residues & 0.218 \\
East Chapman in 2001 on 6-month-old residues & 0.119 \\
East Chapman in 2001 on 18-month-old residues & 0.118 \\
Wongan Hills in 2001 on 6-month-old residues & 0.602 \\
\hline
\end{tabular}

such a rapid discharge of ascospores under the environmental conditions of Kentucky and it appears that pseudothecia may have developed before harvest under those conditions. However, in the current studies, we found that the discharge of ascospores on any given day was negatively correlated with accumulated temperature, maximum temperature, evaporation, minimum and maximum soil temperature, and solar radiation and was positively correlated with the minimum temperature, rain, and minimum relative humidity.

The ascospore discharge pattern was found to be similar regardless of the age of the residues, except that the number of ascospores discharged from 18-month-old residues was substantially reduced, particularly when the residues were raked and burnt in the previous year. This observation supports the findings of other studies $(8,14,15)$ that the number of ascospores released from 2-year-old residues are much lower than from the fresh residues. No apparent diurnal pattern of ascospore discharge was observed in the present investigations as reported from Eastern Australia (15). In contrast, a diurnal dispersal pattern of ascospores was observed in Canada (7).

Our study is the first report describing the maturation of pseudothecia and discharge of ascospores under different field conditions of Western Australia. In current studies, an attempt was made to model the discharge of ascospores during the season. A regression model excluding location and year effects fitted the accumulated data very well at all sites except Wongan Hills, where the fitted model predicted higher ascospore numbers at an earlier date than occurred. Although there were significant location effects, indicating that ascospores discharged in higher numbers at some locations than others, there were no year effects once weather variables had been included in the model, and there were no interactions between location and weather variables. This indicates that differences in the pattern of ascospore discharge between locations and years included in this study can be explained by direct effects of weather variables on ascospore discharge or indirect effects through maturation of pseudothecia which is highly correlated with ascospore discharge. Further refinement in this model could help with forecasting the actual number of ascospores discharging during the crop growth. This could provide growers with some flexibility in choosing their management strategies; in particular, with having the option of using foliar application of fungicides to manage blackleg. In addition, work done by Wherrett et al. (30) and Khangura (10) indicates that it is possible to manipulate the amount of ascospores discharged in the field and that this could help in minimizing the impact of blackleg disease (31). There would be significant benefits from undertaking further investigations to define the minimum thresholds of actual ascospores discharged for severe disease to occur in commercial crops across the different rainfall zones of the Western Australian grain belt.

\section{ACKNOWLEDGMENTS}

The Australian Grains Research and Development Corporation (GRDC) provided funds for this research. We thank J.-N. Aubertot,
INRA, France for critically reviewing the manuscript; and D. Jorgensen, M. Aberra, and T. Trent for providing excellent technical assistance.

\section{LITERATURE CITED}

1. Aubertot, J-N., Pinochet, X., and Doré, T. 2004. Analysis of the effects of sowing date and nitrogen availability during vegetative stages of on Phoma stem canker (Leptosphaeria maculans) development on two winter oilseed rape cultivars. Crop Prot. 23:635-645.

2. Bokor, A., Barbetti, M. J., Brown, A. G. P., MacNish, G. C., and Wood, P. McR. 1975. Blackleg of rapeseed. J. Agric. West. Aust. 16:3-7.

3. Brunin, B., and Lacoste, L. 1970. Recherches sur la maladie du colza due à Leptosphaeria maculans (Dem.) Ces. \& Not. II. Pouvoir pathogène des ascospores. Ann. Phytopathol. 3:477-488.

4. Canola Association of Australia. 2004. CAA forecast Dec 2004. Online publication. www.canolaaustralia.com/operations/crop_forecast

5. Gladders, P., and Musa, T. M. 1980. Observations on the epidemiology of L. maculans stem canker in winter oilseed rape. Plant Pathol. 29:28-37.

6. Gosende, S., Penaud, A., Aubertot, J. N. Schneider, O., and Pinochet, X. 2003. Evolution of soil surface oilseed rape stubbles and their ability to produce spores of Leptosphaeria maculans: Preliminary results. Pages 1166-1168 in: Proc. 11th Int. Rapeseed Congr. Copenhagen, Denmark.

7. Guo, X. W., and Fernando, W. G. D. 2005. Seasonal and diurnal patterns of spore dispersal by Leptosphaeria maculans from canola stubble in relation to environmental conditions. Plant Dis. 89:97-104.

8. Hershman, D. E., and Perkins, D. M. 1995. Etiology of canola blackleg in Kentucky and seasonal discharge patterns of Leptosphaeria maculans ascospores from infected canola stubble. Plant Dis. 79:1225-1229.

9. Huang, Y. J., Fitt, B. D. L., Jedryczka, M., Dakowska, S., West, J. S., Gladders, P., Steed, J. M., and Li, Z. Q. 2005. Patterns of ascospore release in relation to Phoma stem canker epidemiology in England (Leptosphaeria maculans) and Poland (Leptosphaeria biglobosa). Eur. J. Plant Pathol. 111:263-277.

10. Khangura, R. 2004. Influence of chemicals on inoculum production by Leptosphaeria maculans on canola (Brassica napus L.) residues. J. Food Agric. Environ. 2:188-192.

11. Khangura, R., and Barbetti, M. J. 2001. Prevalence of blackleg (Leptosphaeria maculans) of canola (Brassica napus) in Western Australia. Aust. J. Exp. Agric. 41:71-80.

12. Khangura, R., and Barbetti, M. J. 2002. Efficacy of Impact to manage blackleg (Leptosphaeria maculans) in canola. Aust. J. Agric. Res. 53:311-321.

13. Khangura, R., and Barbetti M. J. 2004. Time of sowing and fungicides affect severity of blackleg (Leptosphaeria maculans) and yield of canola (Brassica napus) in Western Australia. Aust. J. Exp. Agric. 44:1205-1213.

14. Marcroft, S. J., Sprague, S. J., Pymer, S. J., Salisbury, P. A., and Howlett, B. J. 2003. Temporal and spatial relationships between inoculum source and severity of blackleg (Leptosphaeria maculans) of canola crops in south-eastern Australia. Aust. J. Exp. Agric. 43:1231-1236.

15. McGee, D. C. 1977. Blackleg (Leptosphaeria maculans (Desm.) Ces. et de Not.) of rapeseed in Victoria: sources of infection and relationships between inoculum, environmental factors and disease severity. Aust. J. Agric. Res. 28:53-62.

16. McGee, D. C., and Petrie, G. A. 1979. Seasonal patterns of ascospore discharge by Leptosphaeria maculans in relation to blackleg of oilseed rape. Phytopathology 69:586-589.

17. Pérès, A., Poisson, B., Le Sourne, V., and Maisonneuve, C. 1999. Leptosphaeria maculans: Effect of temperature, rainfall and humidity on the formation of pseudothecia. Proc. 10th Int. Rapeseed Congr. Canberra, Australia. Online publication/au/gcirc/3/106.

18. Pérès, A., Poisson, B., Penaud, A., Jain, L., and Pilorge 1999. Leptosphaeria maculans (Phoma lingam): A summary of three years of epidemiological studies (1995, 1996 and 1997). Proc. 10th Int. Rapeseed Congr. Canberra, Australia. Online publication /au/gcirc/3/105.

19. Petrie, G. A. 1995. Long-term survival and sporulation of Leptosphaeria maculans (blackleg) of naturally-infected rapeseed/canola stubble in Saskatchewan. Can. Plant Dis. Surv. 75:23-34

20. Petrie, G. A. 1995. Patterns of ascospore discharge by Leptosphaeria maculans (blackleg) from 9- to 13-month-old naturally infected rapeseed/canola stubble from 1977 to 1993 in Saskatchewan. Can. Plant Dis. Surv. 75:35-43.

21. Poisson, B., and Pérès, A. 1999. Studies related to maturation of Leptosphaeria maculans pseudothecia on rapeseed residues infected by stem canker. Proc. 10th Int. Rapeseed Congr. Canberra, Australia. Online publication/au/gcirc/3/109.

22. Rempel, C. B., and Hall, R. 1993. Dynamics of ascospores of blackleg in autumn on stubble of the current year's crop of spring rapeseed. Can. J. Plant Pathol. 15:182-184.

23. Rossi, V., Ponti, I., Marinelli, M., Giousè, S., and Bugiani, R. 2000. A new model estimating the seasonal pattern of air-borne ascospores of Venturia 
inaequalis (Cook) Wint. in relation to weather conditions. J. Plant Pathol. 82:111-118.

24. Salam, M. U., Khangura, R. K., Diggle, A. J., and Barbetti, M. J. 2003. Blackleg Sporacle: A model for predicting onset of pseudothecia maturity and seasonal ascospore showers in relation to blackleg of canola. Phytopathology 93:1073-1081.

25. Salisbury, P. A., Ballinger, D. J., Wratten, N., Plummer, K. M., and Howlett, B. J. 1995 Blackleg disease on oilseed Brassica in Australia: A review. Aust. J. Exp. Agric. 35:665-672.

26. Toscano-Underwood, C., Huang, Y. J., Fitt, B. D. L., and Hall, A. M. 2003. Effects of temperature on maturation of pseudothecia of Leptosphaeria maculans and L. biglobosa on oilseed rape stem debris. Plant Pathol. 52:726-736.

27. Thürwächter, F., Garbe, V., and Hoppe, H. 1999. Ascospore discharge, leaf infestation and variations in pathogenicity as criteria of predict impact of Leptosphaeria maculans on oilseed rape. J. Phytopathol. $147: 215-222$.
28. West, J. S., Fitt, B. D. L., Leech, P. K., Biddulph, J. E., Huang, Y. J., and Balesdent, M. H. 2002. Effects of timing of Leptosphaeria maculans ascospore release and fungicide regime on Phoma leaf spot and Phoma stem canker development on winter oilseed rape (Brassica napus) in southern England. Plant Pathol. 51:454-463.

29. West, J. S, Kharbanda, P. D. Barbetti, M. J., and Fitt, B. D. L. 2001. Epidemiology and management of Leptosphaeria maculans (Phoma stem canker) on oilseed rape in Australia, Canada and Europe. Plant Pathol. 50:10-27.

30. Wherrett, A. D, Sivasithamparam, K., and Barbetti, M. J. 2003. Chemical manipulation of Leptosphaeria maculans (blackleg disease) pseudothecial development and timing of ascospore release from canola (Brassica napus) residues. Aust. J. Agric. Res. 54:837-848.

31. Wherrett, A. D, Sivasithamparam, K., and Barbetti, M. J. 2004. Establishing the relationship of ascospore loads with blackleg (Leptosphaeria maculans) severity on canola (Brassica napus). Aust. J. Agric. Res. 55:849-854. 